\title{
Technology value analysis of the ship contract design value stream
}

\author{
Richard Lee Storch ${ }^{1}$ and Matt Williamson ${ }^{2}$ \\ ${ }^{1}$ Industrial Engineering, University of Washington, Box 352650, Seattle, WA 98195 - 2650, \\ USA. \\ Email: rlstorch@u.washington.edu \\ ${ }^{2}$ Business performance Group, LLC, 5301 Shilshole Ave. NW, \#330, Seattle, WA 98107 - \\ 4079, USA. \\ Email:matt@bpgllc.com
}

\begin{abstract}
Value stream mapping and analysis has been successfully applied to many processes in order to identify areas for process improvement. This tool is especially important for processes that span multiple organizations, a relatively long time period, and have substantial impact on the overall profitability of the enterprise or the success of a specific project. The critical importance of design to productivity has been established in many industries. Industries that produce large, one-of-a-kind products are especially impacted by the design. Shipbuilding is a prime example of this situation. Each ship design project typically results in one or a small number of products. The ship design process, especially in the United States, spans multiple companies. The process steps include concept design, preliminary design, contract design and detail design. The first step of the process (concept design) is typically performed by independent naval architects, working for ship owners/operators. Preliminary design and contract design are commonly done by the shipbuilder. Detail design is often done by independent naval architects, working for the shipyard. Even in companies where all design stages are performed internally, the organization of the work is usually such that the tools used and the information generated are not easily transferred from one function to the other. Thus, value stream mapping and analysis offers the potential to greatly improve the ship design process.

Evaluation of potential technology investments to improve a value stream has primarily been without a structured approach, and without correlation to an overall business plan. The technology value analysis methodology has been shown to offer the opportunity to align process improvement and technology investment decisions with the strategic goals of an organization. Value stream mapping provides an insightful view of the process steps, and identifies where value is created and how it is moved. Based on this map, metrics to monitor and evaluate various steps in the process can be developed. These metrics can also be correlated with business strategy and goals. Then, the technology investment analysis methodology can be employed to prioritize improvements that offer the best return in terms of improvement of the value stream and it's alignment with business strategy.

The combination of these two tools adds robustness to evaluation of possible technological improvements to a process, by both considering the overall value stream and the alignment to company strategic goals. This concept is presented using a simplified model of the ship design process as a case study.
\end{abstract}


Keywords

Value stream mapping, technology value analysis, ship design.

\section{INTRODUCTION}

In order to improve the contract design process for shipyards, a variety of new tools and ideas can be combined. The product-oriented production and design methodology offers the opportunity for shipbuilders to increase the speed and reliability and simultaneously reduce the risks associated with developing and bidding contract designs. Associated with this new approach, there is a need to evaluate what new technologies are required to effectively employ this approach. The value stream of this approach to rapid development of contract designs can be developed. Based on this, technology value analysis can be employed to evaluate the need for new technological approaches to the process. After defining the value stream represented by this new approach to the contract design process, technology value analysis will be employed to consider new technologies that can be most effectively implemented.

\section{VALUE STREAM MAPPING}

Lean thinking is based on five general principles, value, value stream, flow, pull, and perfection. "The value stream is the set of all the specific actions required to bring a specific product (whether a good, a service, or increasingly, a combination of the two) through the three critical management tasks of any business: the problem-solving task running from concept through detailed design and engineering to production launch, the information management task running from order-taking through detailed scheduling to delivery, and the physical transformation task proceeding from raw materials to a finished product in the hands of the customer." (Womack and Jones, 1996)

The tool used to analyze the process from the perspective of waste elimination is called value stream mapping. (Lovelle, 2001) Although still somewhat ill-defined, value stream mapping is intended to describe the process steps that add value to a specific product or service under consideration. The ultimate goal is to benchmark the current process with a proposed future vision of the process by evaluating every step as value adding, non-value adding but necessary given the current technology and non-value adding. (Hines and Rich, 1997) In general, the approach is to seek to immediately eliminate the third category, and then to seek means of minimizing or eliminating the second category. There are many examples of the use of value stream mapping of products in manufacturing companies (Womack and Jones, 1996, Liker, 1998), but fewer examples in service or design situations.

\section{Value Stream Map of the Contract Design Process}

The first step in a technology value analysis of the design process is a process flow definition of the process. As a first step, a simplified value stream map can be 
developed for the design process. For this analysis, the design process will be described in terms of the stages of concept design, preliminary design, contract design, transition design and detail design (see Figure 1).

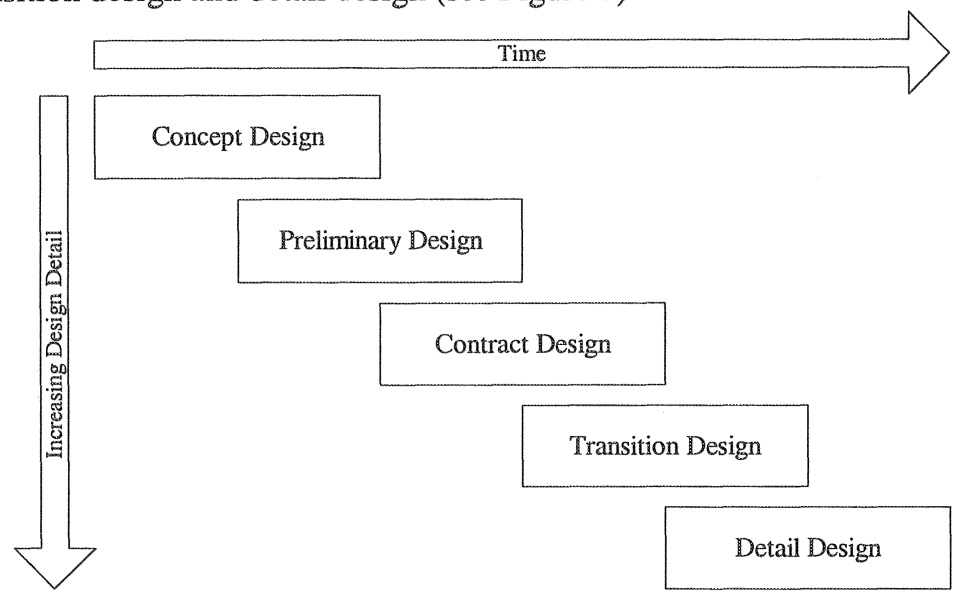

Figure 1 - Ship Design Process

Ultimately, the efficient development of information requires building seamlessly on increasing levels of detail as the design progresses. Additionally, the value streams diverge as the information is generated for different users. In order to envision the potential combination of the two techniques of value stream mapping and technology value analysis, the initial design stages only will be addressed. This entails the development of the design from concept through contract design. The value stream for this design process has two primary end points, the customer, who approves and accepts the contract design package, and the manufacturing (shipbuilding) system, essentially the work stations that perform the actual manufacturing and assembly processes. There can be considered to be two other major value stream destinations, however. These are suppliers, whose equipment and components will be chosen by the shipbuilder and customers for use in interim products, and the regulatory bodies, who must approve the final detail design products. 


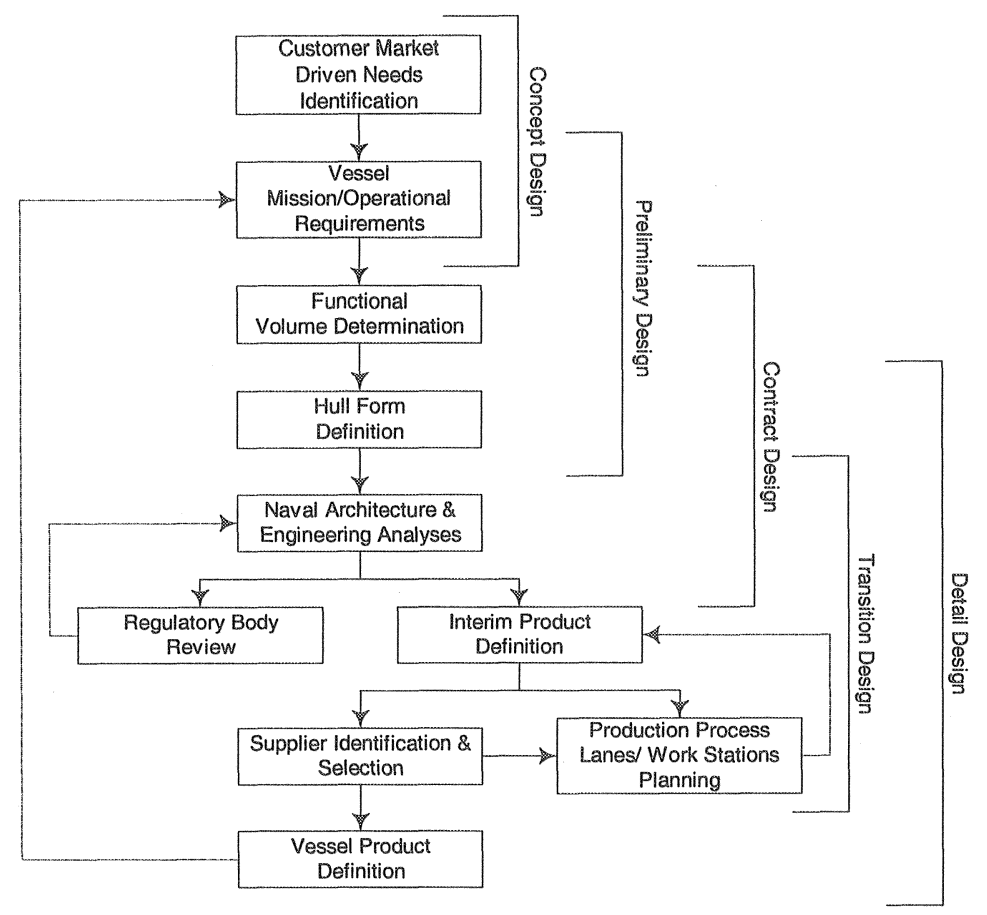

Figure 2 - Ship Design Value Stream

The bifurcated design process value stream, from concept to contract design, can be simply represented by Figure 2. The process is begun when a customer identifies a market need for a ship. This drives the development of a set of mission or operational requirements. An example of this can be a need to carry 4000 TEU of containers from Asia to the U. S. West Coast, with a given service schedule. The concept design process then begins, with the goal of rapidly developing the information needed for a contract design package that satisfies the customers requirements, is of sufficient detail so that both customer and shipbuilder understand the vessel under consideration, and so that a low risk estimate of cost and schedule can be developed.

The design process has recently been revised to help achieve this rapid response requirement. The new approach is based on the functional volume concept. (Tomassoni, Huynh, et al., 2002) Based on previous experience, a shipbuilder would develop a "family album" of functional volumes, tailored to the product mix that represents the market of the shipyard. The functional volume categories are cargo space, engine room, bow, and accommodations. Figure 3 is an example of a family album. The required volume is determined parametrically, based on the ship type and the new requirements. Because there is prior experience with the volumes in the family album, the shipbuilder has high confidence that the volume will be sufficient to satisfy the customer requirements, and also that the cost to build this interim product is easily predicted. 
Once the functional volumes have been chosen and parametrically sized for the design under consideration, the hull form can be wrapped around the volumes. Once again, because of the prior experience with these functional volumes, there is high confidence that sufficient volume is available for all necessary features. This includes distributed system runs (piping, electrical, HVAC, etc.), plus passageways, and other requirements not directly related to the primary function of that volume (i.e. cargo carrying capacity). The hull form, as developed, provides the necessary data to develop the 3D model upon which all subsequent naval architectural calculations and analysis is performed. Figure 4 shows the process for developing the hull form.

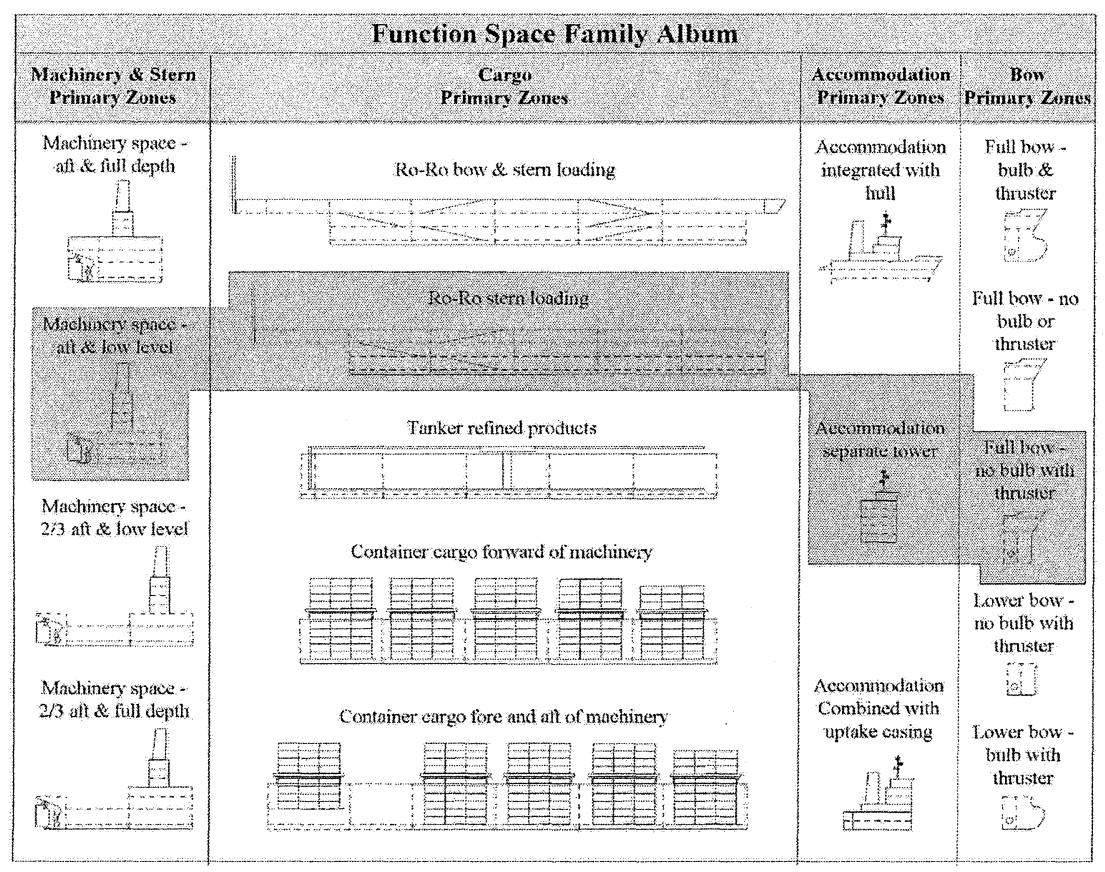

Selection of the functional spaces

The initial configuration for vessel can be created from a combination of the various zonal functional spaces shown in the "Function space family album" which produces the vessets basic lavoui.

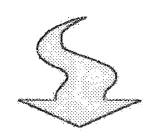

Effect of interima nroducts

The actual size of the vessel is not determined only by the selection of functional spaces. It is also partly set by the size and type of interim product a shipyard can build cost effectively.

Initial Vessel Configuration

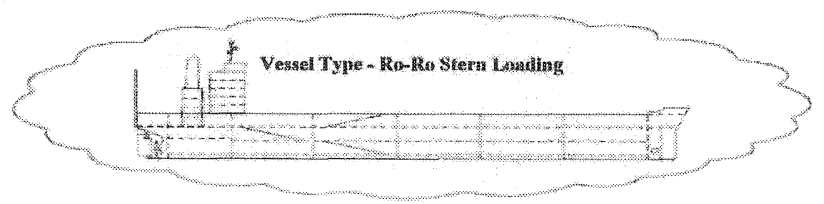

Figure 3 - Functional Volume "Family Album" Example (Tomassoni, Huynh, et al., 2002 and First Marine International, 2002) 


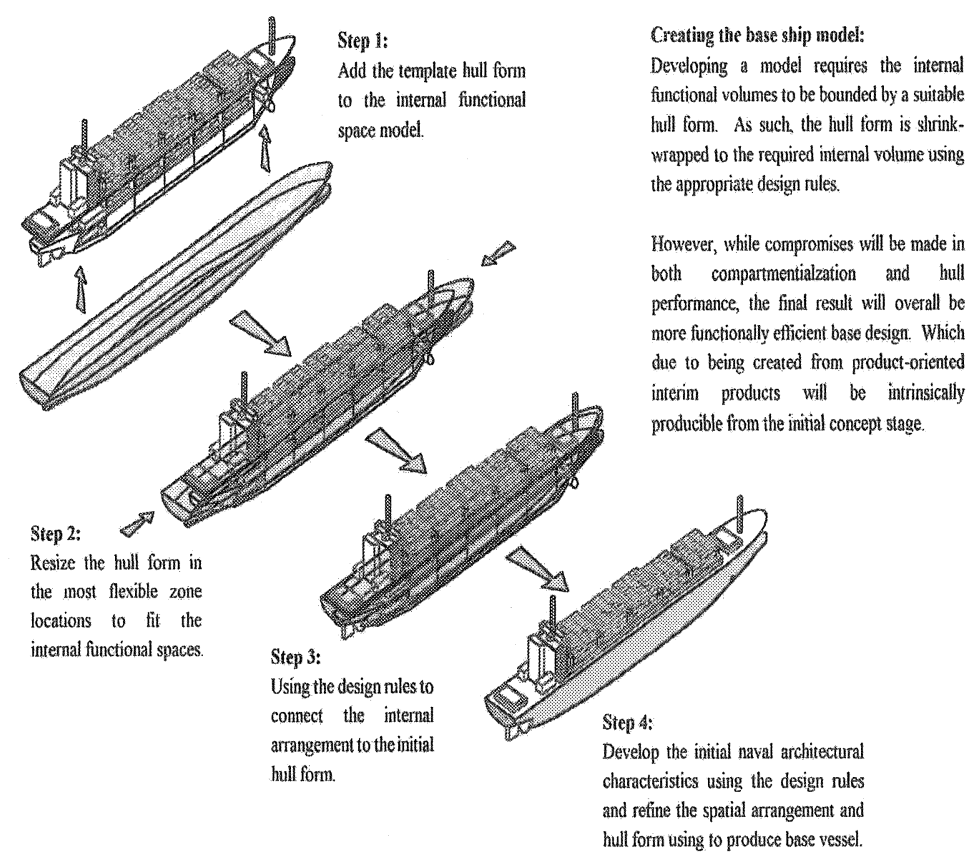

Figure 4 - Wrapping the full form around the functional volumes (Tomassoni, Huynh, et al., 2002 and First Marine International, 2002)

Based on this hull form, the next step in the value stream is evaluating the hull form as developed. A variety of analyses are required at this stage, including hydrostatics, intact and damaged stability, longitudinal strength, and resistance and powering. The overall process is shown in Figure 5. 


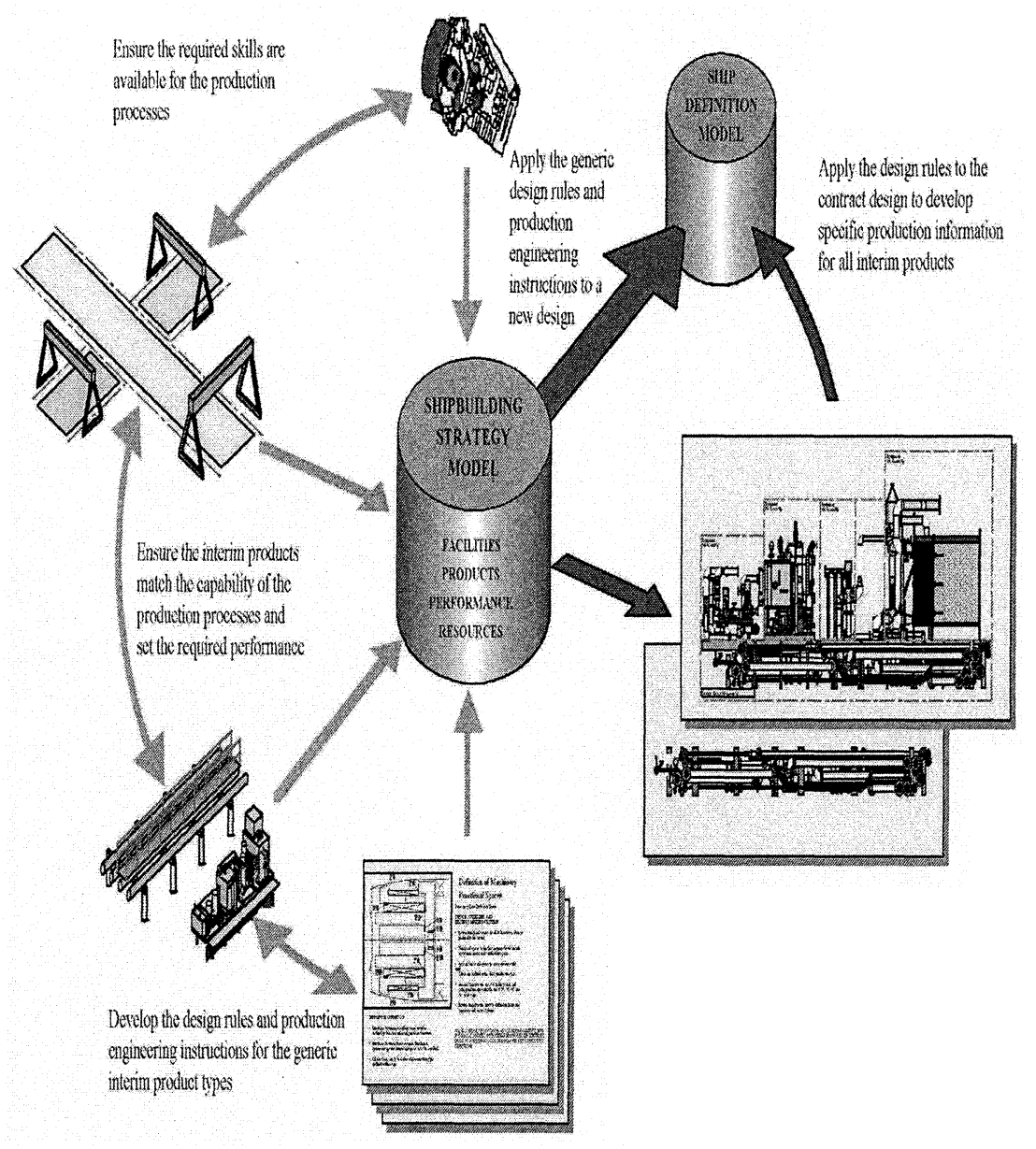

Figure 5 - Overall functional volume design approach (First Marine International, 2002)

In Figure 5, the central shipbuilding strategy model is a database that contains the preferred shipyard approaches to production, including the functional volume family album, the design rules used to develop and evaluate new designs and the components and production standards preferred by the shipbuilder. As a new contract design is developed, a project specific database, represented in the upper right hand corner of Figure 5 is developed. It is this database that initially contains the specific 3D hull form data that is to be analyzed using the naval architectural analysis programs necessary to confirm the viability of the design. This "smart product model" is then evaluated using the cost estimating capabilities to produce a contract design package that is both inherently producible and which has a cost estimate that can be made with high confidence. (Ross, McNatt, et al., 2002) 


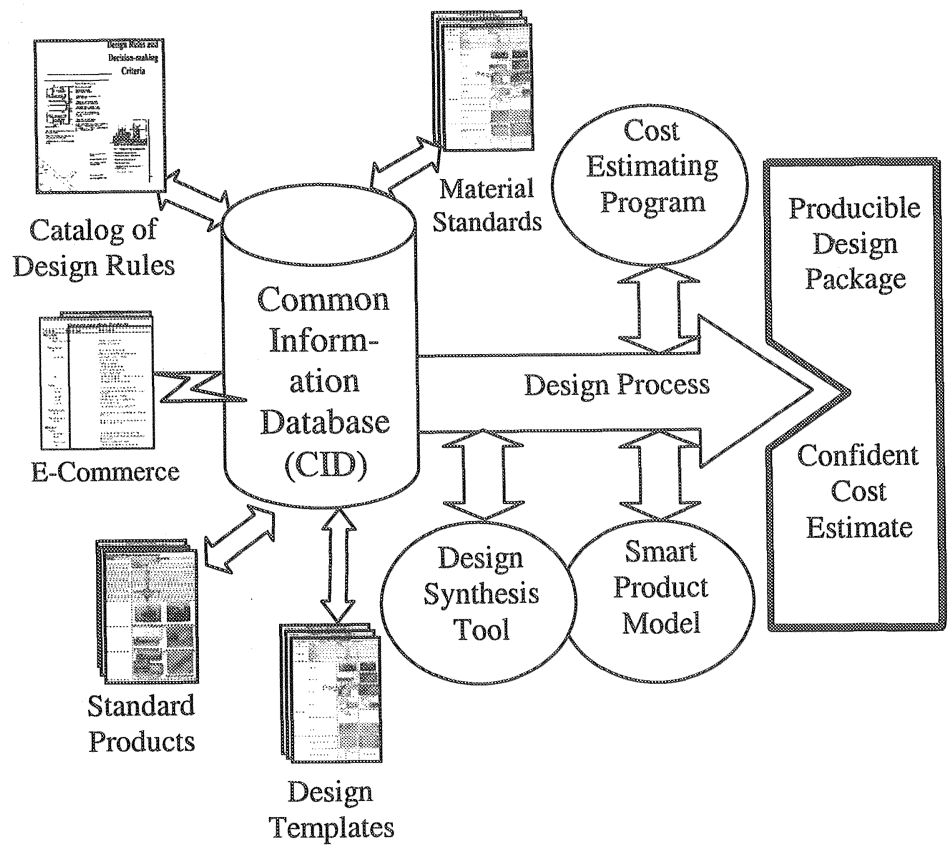

Figure 6 - The functional volume based design process (First Marine International, 2002)

At this point, the result of the design process is information that can be used to begin the regulatory review process and a definition of interim products that can then be provided to both suppliers for evaluation of equipment and component needs, and to workstation planners to begin the planning and scheduling process for production. Ultimately, the vessel product definition can be evaluated against the customer wants as the final part of the vessel design value stream.

\section{CONTRACT DESIGN PROCESS DEFINITIIONS}

The stages of contract design, as shown in Figure 2, are Functional Volume Determination, Hull Form Definition, Naval Architecture and Engineering Analyses, and Interim Product Definition. Table 1 shows the process steps within each of these stages.

Performing each of these processes requires some level of technology, not only to perform the specific analyses, but also to ensure integrated communication and cooperation amongst each of the other processes that are impacted. In managing and improving the performance and interaction of these processes, shipbuilders must make critical decisions related to investments in developing and/or acquiring, and implementing these often advanced technologies; however, without the proper analyses, the precise process impacts and true value of any technology can be difficult to define. 
Table 1-Contract Design Processes

\begin{tabular}{|c|c|}
\hline Contract Design Stage & Design Process \\
\hline \multirow{3}{*}{ Functional Volume Determination } & Functional Volume Selection \\
\hline & Determination of Interim Products \\
\hline & Initial Vessel Configuration \\
\hline \multirow{4}{*}{ Hull Form Definition } & Payload Definition \\
\hline & Hydrodynamics Analysis \\
\hline & Power and Resistance Analysis \\
\hline & Manoeuvring Analysis \\
\hline \multirow{8}{*}{$\begin{array}{l}\text { Naval Architecture/Systems Design \& } \\
\text { Analyses }\end{array}$} & Hull Structure \\
\hline & Ballast \\
\hline & Power Distribution \\
\hline & Navigation \\
\hline & Communications \\
\hline & Accommodation \\
\hline & Payload Handling \\
\hline & Fire Protection \\
\hline \multirow{4}{*}{ Interim Product Definition } & Major Equipment Identification \\
\hline & Supplier Identification \\
\hline & Design for Production \\
\hline & Production Planning \\
\hline
\end{tabular}

\section{Complex technology investment analysis criteria}

Many methodologies have been used attempting to understand and mitigate the inherent risks, and to meaningfully estimate the value on advanced technology implementations. Traditionally, technology implementation decision-making has been based upon the standard tools of engineering economics, such as Present Worth, Return on Investment, and Cost-Benefit analyses. These methods are useful for determining comparative valuations for selected technology options. However, they do not possess qualities that are essential in measuring the full effect of complex technology on an organization. An analysis of complex technology investment must:

- Be driven by the organizational needs;

- Be objective, structured, and rational, utilizing expert knowledge and data acquired from organizational processes and technology functions to the greatest extent possible;

a $\mathrm{Be}$ ongoing because technology, and business and organizational environments are always changing;

" Explicitly account for risk; and

a Account for the value of potential future options inherent in any given investment strategy. 


\section{Process Functionality/Capability Identification}

When conducting an initial needs analysis for a new technology, no data from implementations of earlier versions are available. Such an analysis is based primarily on expert knowledge, opinion, and on information obtained from outside sources. Given the lack of objective internal data, this initial needs analysis is inherently qualitative, and highly dependent upon the quality of expert knowledge and outside information. It is also dependent upon the analysis procedure, which must facilitate generation of meaningful results from qualitative information. This initial analysis must incorporate a means of determining the uncertainty, robustness, and risk of the results.

The first step toward this initial analysis is for the organization to identify and define a set of functionalities and/or capabilities that are necessary to carryout the business processes within the stages of the value stream. Figure 7 shows a sample list of functionalities (across the top of the Figure) that may be necessary to carryout the design processes within the contract design value stream (down the side of the Figure). The next steps, also illustrated in Figure 7 are to develop an initial ranking of functionality relative importance within the value stream. This is done by determining relative weightings for each of the design processes and identifying the strengths of the relationships between design processes and system functionalities. This process has been described in a previous paper developed by the authors (Spicknall, et al., 2000).

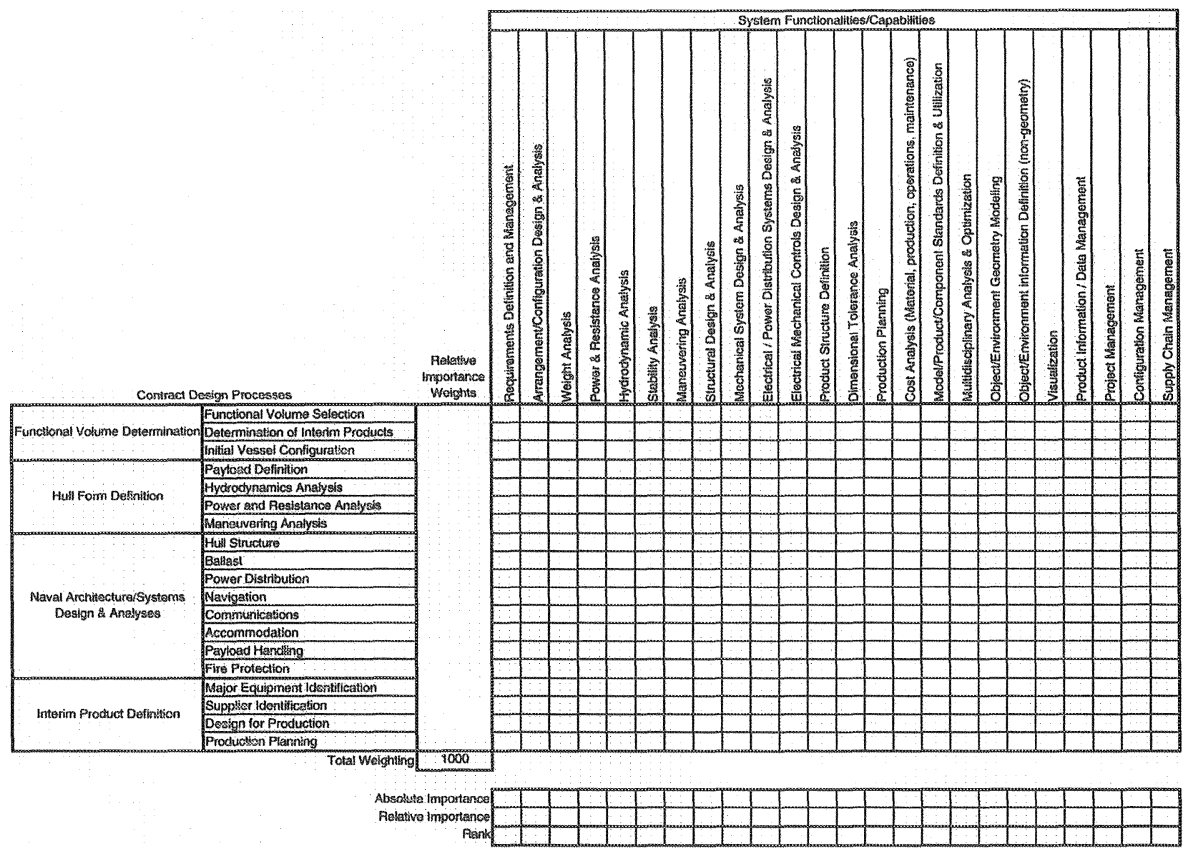

Figure 7 - Contract Design Process / System Functionality Matrix 
Functionalities are identified independent of the technologies that are ultimately acquired. In order to identify the necessary technologies (i.e., software and hardware that represent instantiations of the system functionalities) a second matrix is prepared with functionalities in rank order along the side and appropriate technologies listed across the top. Technologies are then ranked. Based on the determination of the associated uncertainty and risk of the results appropriate financial allocations can be made toward acquisition and implementation of the necessary technologies.

\section{METRICS DEFINITION AND COLLECTION}

After a new technology is implemented, upgrades, improvements, or replacement will be required in the future. In evolving a technology it is helpful to know from the implementations of earlier versions which specific technology functionalities had the greatest impact on the process.

In order to do this, the organization must define business metrics by process or intermediate product, and technology functionality metrics. Data are then collected for each set of metrics during each iteration of technology implementation. Process metrics typically relate to cost, time, and quality. Technology functionality metrics are in the language of the technologist. For example, for the technology functionality "graphics resolution," the metric might be dpi (dots per inch).

Once data are collected, it is possible to statistically determine what correlation exists between changes in the technology performance and the effectiveness/efficiency of each process. The degree of correlation and the associated correlation coefficients can then be used as the basis for the next round of investment decisions. These types of statistical analyses also provide confidence intervals that represent uncertainty or risk.

\section{CONCLUUSIONS}

Intelligent integration of information and communications technologies within a value stream is essential to the business success of any organization. This paper has taken a look at combining value stream mapping and technology value analysis techniques to ensure that business processes within the value stream are identified and that technologies necessary to enable these processes are intelligently implemented.

By combining these techniques, organizations can begin to identify how collaboration amongst each of the design processes and value stream stages are integrated. Further, the priorities of an organization in terms of process integration, collaboration with suppliers and regulatory bodies and customers are identified. Identification of these priorities is manifested by the organization's determination of system functionalities and its identification relationship strengths with its business processes. It is these priorities that determine the degree that an organization will focus on acquiring information and communication technologies that enable internal and external collaboration. 


\section{Further research}

This paper has presented a case study focused on the contract design stages within the ship design and construction value stream. Using the design processes within the contract design stages of the ship design value stream, technology value analysis tools have been employed to show how intelligent decisions for the acquisition and deployment of technologies upon which these processes depend. However, as presented in Figure 2, the value stream of the ship design process involves more than the contract design stages.

The authors believe that there are two additional avenues of further research. First, it is recognized that variations in design processes will occur as different vessel configurations are selected from the family album as shown Figure 3. Shipbuilders have developed these portfolios of design that represent their product line. Research is necessary to develop a methodology for optimizing technology acquisitions that allow effective integration of all design processes across vessel families.

Secondly, technology value analyses can be conducted along all stages of the value stream. Additional case studies need to be identified that will allow for research into methodologies that simplify identification of technology integration at transition points between the individual design and production stages.

\section{REFERENCES}

[1] First Marine International, unpublished study materials, 2002.

[2] Hines, Peter, and Rich, Nick, "The seven value stream mapping tools," International Journal of Operations \& Production Management, Vol. 17, No. 1, 1997.

[3] Liker, Jeffrey, Becoming Lean, Inside Stories of U.S. Manufacturers, Productivity Press, Portland, Oregon, 1998.

[4] Lovelle, Jared, "Mapping the value stream," IIE Solutions, Vol. 33, No. 2, Feb. 2001.

[5] Ross, Jonathan, McNatt, Tobin, and Hazen, George, "The Project 21 Smart Product Model, A New Paradigm for Ship Design, Cost Estimation and Production Planning," Journal of Ship Production, Vol. 18, No. 2, May 2002.

[6] Spicknall, Mark, Williamson, Matt, and Storch, Richard, "Technology value analysis," Information and Communication Technology in Logistics and Production Management, Conference Proceedings, Tromso, Norway, June 2000.

[7] Storch, Richard, Hammon, Colin, Bunch, Howard, and Moore, Richard, Ship Production, $2^{\text {nd }}$ Edition, Cornell Maritime Press, Centreville, Maryland, 1988.

[8] Tomassoni, Carlos, Huynh, Ted, and Schiller, Thomas, "Production-based Design Methodology for Shipboard Machinery Spaces," Ship Production Symposium, Conference Proceedings, Boston, Sept. 2002.

[9] Womack, James, and Jones, Daniel, Lean Thinking, Simon and Schuster, New York, 1996. 